\title{
CHALLENGES
}

\section{Paediatrics in the Netherlands: challenges for today and tomorrow}

\author{
Henk K A Visser
}

This is the eighth paper in a series showing the problems facing the medical services for children in different countries.
Erasmus University and Department of Paediatrics, University Hospital, Rotterdam,

Correspondence to: Professor H K A Visser, Sophia Children's Hospital, Gordelweg 160, 3038 GE Rotterdam, The Netherlands. The Netherlands

The Dutch Paediatric Society had its 100th anniversary in 1992. Paediatrics in the Netherlands has changed in a remarkable way particularly during the last 25 years and the number of paediatricians has more than doubled. Paediatrics is nowadays a popular specialty for medical students and there are (too) many applications for specialty training. Many new hospitals - with departments of paediatrics - have been constructed. There are now eight university departments of paediatrics, which include three children's hospitals. Most of them are in new buildings and the others will follow within the next few years. A large number of young paediatricians have been trained abroad in (clinical) research and have returned to their home country. The paediatric research output has increased considerably. The health status of Dutch children is good. The country has an excellent health care delivery system also for children - with universal coverage and so far no serious financial limitations.

One may conclude that paediatrics in the Netherlands is doing well. This is true, but there are some problems. Costs of health care are rising and there are now political discussions about cost and health effectiveness and efficiency. The population is aging and an increasing proportion of health expenditure will go to geriatric care. For paediatrics the challenge for the future is to get its adequate share of the national health budget, while maintaining the quality of care.

There are a number of basic issues in Dutch paediatrics, which will be mentioned in this article: (i) the integration of health services both curative and preventive - with appropriate regionalisation, (ii) paediatric manpower planning, and (iii) quality control of services. Furthermore, I will discuss some problems and developments in perinatal care and deal with the increasing importance of medical ethical problems in paediatrics. Finally, I will mention the present day discussions on non-therapeutic research in children that are taking place in the Dutch parliament.

Table 1 Infant mortality and perinatal mortality in the Netherlands 1980-91 (data from Central Bureau for Statistics)

\begin{tabular}{lrllll} 
& 1980 & 1985 & 1989 & 1990 & 1991 \\
\hline Infant mortality (per 1000 live births) & $8 \cdot 6$ & $8 \cdot 0$ & $6 \cdot 8$ & $7 \cdot 1$ & $6 \cdot 5$ \\
Perinatal mortality (per 1000 births) & $11 \cdot 1$ & $9 \cdot 8$ & $9 \cdot 6$ & $9 \cdot 6$ & $9 \cdot 1$ \\
Stillbirths (per 1000 births) & $6 \cdot 6$ & $5 \cdot 9$ & $5 \cdot 8$ & $5 \cdot 7$ & $5 \cdot 3$ \\
Neonatal mortality (0-7 days) (per 1000 live births) & $4 \cdot 5$ & $4 \cdot 0$ & $3 \cdot 8$ & $3 \cdot 9$ & $3 \cdot 8$
\end{tabular}

Some general demographic and economic background data and selected health status indicators

The Netherlands has about 15 million inhabitants, of which about 5\% (0.7 million) are of non-Dutch origin. The Netherlands is now a multiracial society with large numbers of immigrants from Surinam, Dutch Antilles, Mediterranean countries (mainly Turkey and Morocco), and recently Asian and African countries. The immigrants live mainly in the large cities (Amsterdam, Rotterdam, The Hague) in the western part of the country (the provinces of North and South Holland). In the Sophia Children's Hospital in Rotterdam about $35 \%$ of the patients are of non-Dutch origin.

In 1991 nearly 200000 children were born (13.2 per 1000 population) and the birth rate has been more or less stable for a number of years. The average length of life in 1991 was 70.9 years for males and $77 \cdot 1$ years for females. Life expectancy at birth was $74 \cdot 1$ years for males and $80 \cdot 2$ years for females. In $199118 \%$ of the population was in the age group $0-14$ years.

Infant mortality and perinatal mortality are very low (table 1). Some general health and lifestyle indices for the Netherlands and some Western European countries are given in table 2. Total health expenditure in 1990 was $8 \cdot 1 \%$ of gross domestic product (GDP) (table 3 ).

\section{Health care delivery for children}

There has always been great emphasis on primary health care in the Netherlands and the general practitioner (GP) is in the centre of the health care system. There are now about 6000 GPs with an average size of practice of about 2500 people. As in the United Kingdom the GP has a primary responsibility for the care of sick children and the paediatrician is a consultant physician and member of a hospital staff. The health insurance system will pay the GP an annual fee per caput for those families with an annual income of less than about 55000 Dutch guilders (about $£ 20750$ ); this includes about $70 \%$ of the population. The other $30 \%$ of the population generally has private health insurance, which will pay the GP per consultation. The paediatrician is paid by the health insurance per consultation but only if the patient is referred by the GP. More than $75 \%$ of paediatricians are now paid by the hospital and have a fixed income, in this situation the 
Table 2 Some general health and lifestyle indices in the Netherlands and other Western European countries (data from Financial Review Health Care 1993, Ministry of Welfare, Health and Culture, the Netherlands)

\begin{tabular}{|c|c|c|c|c|c|}
\hline & $\begin{array}{l}\text { The } \\
\text { Netherlands }\end{array}$ & Belgium & Denmark & $\begin{array}{l}\text { Germany } \\
\text { (West) }\end{array}$ & $\begin{array}{l}\text { United } \\
\text { Kingdom }\end{array}$ \\
\hline Life expectancy at birth (1988) & $77 \cdot 1$ & $74 \cdot 8(1986)$ & $75 \cdot 1$ & $76 \cdot 0$ & $75 \cdot 4$ \\
\hline Life expectancy at 65 years $(1988)$ & $17 \cdot 0$ & $15.9(1986)$ & $16 \cdot 2$ & $16 \cdot 6$ & $16 \cdot 0$ \\
\hline Standardised death rate per 100000 population (1986) & 748 & $879(1986)$ & 867 & 811 & 854 \\
\hline Infant mortality (1989) & $6 \cdot 8$ & $8 \cdot 7$ & $8 \cdot 0$ & $7 \cdot 4$ & $8 \cdot 4$ \\
\hline Daily intake kcal per caput $(1988)^{\star}$ & 3050 & 3460 & 3675 & 3537 & 3062 \\
\hline Alcohol consumption in litres $(100 \%)$ per caput (1990) & $8 \cdot 2$ & $9 \cdot 9$ & $9 \cdot 9$ & $10 \cdot 6$ & $7 \cdot 6$ \\
\hline Cigarettes per caput (1987) & 1042 & 1328 & 1629 & 2030 & 1669 \\
\hline
\end{tabular}

${ }^{\star} 1 \mathrm{kcal}=4 \cdot 18 \mathrm{~kJ}$.

Table 3 Total health expenditure as \% of GDP per caput per year in the Netherlands and other Western European countries (data from the Organisation for Economic Cooperation and Development and the World Health Organisation/Europe, 1990)

\begin{tabular}{lll}
\hline & $\begin{array}{l}\text { Total health } \\
\text { expenditure } \\
(1990) \\
(\% \text { GDP) }\end{array}$ & $\begin{array}{l}\text { Per caput per } \\
\text { year (as US } \\
\text { dollars, } \\
\text { index 1993) }\end{array}$ \\
\hline The Netherlands & $8 \cdot 1$ & 1.500 \\
Germany (West) & $8 \cdot 1$ & 1.899 \\
Denmark & $6 \cdot 2$ & 1.587 \\
Belgium & $7 \cdot 4$ & 1.444 \\
United Kingdom & 6.1 & 1.039 \\
\hline
\end{tabular}

consultation fees go to the hospital. In a recent study the Western industrialised nations were compared on the basis of three characteristics: the extent of their primary health service, their levels of 12 health indicators (as infant mortality, life expectancy, and age adjusted death rates), and the satisfaction of their populations in relation to overall costs of the systems. ${ }^{1}$ The Netherlands and Sweden had the highest ratings for all three measures. One would think that on the basis of such data Dutch politicians would be satisfied. Apparently this is not so, as there is a strong political pressure nowadays to strengthen primary health care, which is supposed to be more cost effective than hospital care.

There are eight medical faculties with university hospitals - all of these have departments of paediatrics - and about 130 other hospitals with paediatric wards. The total number of paediatric hospital beds estimated for 1995 is 4400 (with an occupancy rate of $75 \%$ ).

The National Hospital Board recently concluded that the minimum size of a paediatric hospital ward should be 30 beds. On the basis of this report about 30 hospitals should close their paediatric wards. There are four children's hospitals left in the country. The oldest (1863) is the Sophia Children's Hospital in Rotterdam, which is part of the University Hospital and will move at the end of 1993 in a new children's hospital connected with the faculty of medicine and the adult University Hospital. The Emma Children's Hospital (1865) in Amsterdam has recently merged with the department of paediatrics at the University Hospital Amsterdam. The Wilhelmina Children's Hospital (1888) in Utrecht is a university hospital and will move in the future to a new children's hospital connected with the faculty of medicine and the adult University Hospital. The Juliana Children's Hospital (1885) in The Hague is still a private hospital, but will merge in the near future with the Red Cross Hospital in The Hague.

The university hospitals have regional facilities for special care and the departments of paediatrics in these hospitals have a varying number of subspecialty divisions (neonatalogy, cardiology, pulmonary diseases, endocrinology, gastroenterology, nephrology, infectious diseases, intensive care, etc). Practically all (high tech) special care is concentrated in the paediatric university departments. There are several arguments in favour of further concentration of special services and care in a limited number of university departments. Also concentration of services and manpower in 15-20 non-university hospitals (2-3 around each university hospital) would improve the quality of care and teaching, but such a process will take time. Regionalisation of hospital care is not a popular topic in the Netherlands.

The increasing emphasis on subspecialty care in the university hospital departments during recent decades has been at the expense of generalist services. There is still an important role for the general paediatrician in the university department as a coordinator for patient care and as a teacher for students and residents. There has been a continuous shift from inpatient care to ambulatory and day care.

The role of the paediatrician in preventive paediatrics is nowadays limited. Community health services (infant and toddler clinics, vaccination, screening, services for disabled children, etc) are mainly provided by specially trained nurses and doctors, but paediatricians and GPs may participate. Dutch children are vaccinated against diphtheria, pertussis, tetanus, poliomyelitis (DPTP) and measles, mumps, rubella (MMR). Vaccination against Haemophilus influenzae type B infections has just started. The vaccination rate is high (>95\% for DPTP, for MMR somewhat less). Since the start of vaccination against poliomyelitis in 1957, the Netherlands has used a Salk vaccine with great success. There have been small periodic outbreaks of poliomyelitis in those population groups that are not vaccinated for religious reasons, but since 1957 there has been no single case in a vaccinated person. All newborns are screened for congenital hypothyroidism and phenylketonuria (with incidences of about 1:3500 and 1:17 000).

From an organisational point of view curative and preventive paediatrics are strictly separated. The Dutch Paediatric Society and the Dutch Child Health Society hopefully will 
Table 4 Total number of registered paediatricians as compared with other specialists and general practitioners (1960-85); this includes paediatricians who are working part time

\begin{tabular}{lrrr}
\hline & 1960 & 1985 & \\
\hline Specialists (total No) & 3732 & 10796 & $(2 \cdot 9 \times)$ \\
Paediatricians & 310 & 735 & $(2 \cdot 4 \times)$ \\
Surgeons & 373 & 925 & $(2 \cdot 5 \times)$ \\
Internists & 484 & 1447 & $(3 \cdot 0 \times)$ \\
Cardiologists & 60 & 409 & $(6 \cdot 8 \times)$ \\
Pulmonologists & 260 & 345 & $(1.3 \times)$ \\
General practitioners & 4343 & 5900 & $(1 \cdot 4 \times)$ \\
\hline
\end{tabular}

Table 5 Paediatricians (per $100000<14$ years) as compared with internists including cardiologists and pulmonologists (per $100000>14$ years) $(1960-85)$

\begin{tabular}{lcc}
\hline & 1960 & 1985 \\
\hline Population of the Netherlands (millions) & $11 \cdot 4$ & $14 \cdot 4$ \\
$<14$ years & $3 \cdot 5$ & $2 \cdot 9$ \\
$>14$ years & $7 \cdot 9$ & $11 \cdot 5$ \\
Paediatricians $/ 100000<14$ years & 9 & 26 \\
Internists $/ 100000>14$ years & 10 & 20
\end{tabular}

cooperate more closely in the future and this may lead to a better integration of paediatric hospital and child health community services.

Many children with chronic illnesses are now surviving beyond the paediatric age group. An increasing number of adolescents with cystic fibrosis, spina bifida, congenital heart disease, inborn errors of metabolism, and other long term chronic diseases have now come under the care of adult services. There is a great need for regular meetings and joint clinics of paediatricians and their adult colleagues to facilitate the transition of these adolescents from the paediatric clinics with their comprehensive team services to the adult hospital centres.

For the coming years it will be very important to evaluate our paediatric services and measure health outcomes in a critical way. Regular site visits of paediatric departments with quality control by peers will make our work.accountable to the public and politicians. Measuring outcomes means that we carefully register what we are doing and emphasise follow up studies. There is a great need for clinical epidemiological studies in paediatrics. We need data on changes in prevalence rates of diseases, the efficacy of the treatment of chronic disorders, and changes in birthweight distribution over time. We want to know how the pattern of services - inpatient care, daycare, ambulatory care, intensive/medium/low

Table 6 Number of paediatricians working in the eight academic centres (approximate numbers)

\begin{tabular}{lll}
\hline & 1960 & 1985 \\
\hline Paediatricians (total No) & 350 & 735 \\
Academic centres & $70(22 \%)$ & $210(29 \%)$ \\
Other & 240 & 525 \\
\hline
\end{tabular}

Table 7 Preliminary estimation of the total number of paediatricians in the year 2000 (fte $=$ full time equivalent consultant positions)

About 90 smaller hospitals with departments of paediatrics (1st echelon) About 16 larger hospitals (1st echelon)

with departments of paediatrics (2nd echelon)

Eight academic centres (1st and 2nd echelon)

Regional special care

Total number (approximately)

Of these are 300 women in part time $(0.5)$ function

Total number of paediatricians needed in 2000 care - is changing. In the Netherlands there are now collaborative working groups on childhood leukaemia, growth hormone treatment, congenital hypothyroidism, phenylketonuria, and others. The Dutch Paediatric Society has started a working group for registration of specific disorders. There are a number of ongoing collaborative follow up studies on (very) low birthweight infants. There is also a comprehensive perinatal and neonatal registration organised by the Dutch Obstetric Society and Dutch Paediatric Society.

\section{Paediatric education and manpower planning}

Paediatrics is now one of the important clinical disciplines in the curriculum of the medical schools in the Netherlands. In the six year curriculum there are generally paediatric lectures in the third and fourth year, and a so called junior and senior clerkship in the fifth and/or sixth year (three and six weeks of teaching and experience, respectively).

Postgraduate training for general practice is three years, for paediatrics five years. Paediatric residency training is concentrated in the eight university departments, but at least one year of the training should be in an affiliated hospital. There are now about 150 paediatric residents in training with an annual 'output' of about 30 per year.

The total number of paediatricians has more than doubled in the last 25 years (table 4), but when calculated per 100000 children less than 14 years of age, the total number has almost tripled (table 5). About $30 \%$ of paediatricians are now working in the academic centres (table 6). There are many vacancies for consultant positions these days and it is expected that the total number of resident positions will be increased. It is somewhat difficult to make a prognosis for the total number of paediatricians needed in the year 2000. The number of women paediatricians will increase (in medical schools more than $50 \%$ of the students are now women), and most of them will work in part time positions. The number of working hours per week will decrease. It can be expected that in the future Dutch paediatricians will work in other countries in the European community. A preliminary prognosis for the year 2000 is about 1000 paediatricians (table 7). Residency training is typical 'in-service training' with structural teaching, which is supervised by a national board. There is no formal examination. After five years one is registered and is eligible for a post as a paediatrician in a hospital, a position comparable with a consultant in the United Kingdom. In all hospitals in the country there is a total paediatric house staff of about $150-200$ young physicians who are not registered as a resident 'in training'; most of them are waiting for such a position. The total number of resident training positions is centrally regulated.

$\begin{array}{rl}90 \times 3= & 270 \mathrm{fte} \\ 16 \times 3= & 48 \mathrm{fte} \\ 16 \times 5= & 80 \mathrm{fte} \\ 8 \times 8= & 64 \mathrm{fte} \\ 8 \times 30= & 240 \mathrm{fte} \\ 700 \mathrm{fte} & 300 \\ 1000\end{array}$

Perinatal care

There have been great changes in perinatal care during recent decades. In the Netherlands 
Table 8 Birth in the Netherlands: place of birth and obstetric assistance (data from Central Bureau of Statistics)

\begin{tabular}{|c|c|c|c|c|c|}
\hline & 1980 & 1985 & 1989 & 1990 & 19 \\
\hline \multicolumn{6}{|c|}{ Obstetric assistance (\%) } \\
\hline $\begin{array}{l}\text { Physician } \\
\text { Midwife }\end{array}$ & $\begin{array}{l}59 \cdot 7 \\
39 \cdot 4\end{array}$ & $\begin{array}{l}57 \cdot 8 \\
41 \cdot 7\end{array}$ & $\begin{array}{l}54 \cdot 0 \\
45 \cdot 5\end{array}$ & $\begin{array}{l}54 \cdot 1 \\
44 \cdot 8\end{array}$ & \\
\hline Both & 0 & 0.4 & 0 & 1.0 & \\
\hline Other & 0 & $0 \cdot($ & 0 . & 0 & \\
\hline \multicolumn{6}{|c|}{ Place of birth (\%) } \\
\hline $\begin{array}{l}\text { Home } \\
\text { Hospital } \\
\text { Other }\end{array}$ & $\begin{array}{r}35 \cdot 4 \\
61 \cdot 3 \\
3 \cdot 3\end{array}$ & $\begin{array}{r}36 \cdot 6 \\
61 \cdot 2 \\
2 \cdot 2\end{array}$ & $\begin{array}{c}33 \cdot 4 \\
64 \cdot 6 \\
2 \cdot 1\end{array}$ & $\begin{array}{r}32 \cdot 1 \\
66 \cdot 2 \\
1 \cdot 6\end{array}$ & \\
\hline
\end{tabular}

Table 9 Infant mortality rates $(<7.0$ per 1000 live births); provisional data ${ }^{2}$

\begin{tabular}{ll} 
Sweden & $3 \cdot 8(1991)$ \\
Japan & $4.5(1991)$ \\
Singapore & $5 \cdot 5(1991)$ \\
Hong Kong & $6 \cdot 1(1991)$ \\
Finland & $6 \cdot 1(1990)$ \\
The Netherlands & $6 \cdot 5(1991)$ \\
Switzerland & $6 \cdot 8(1991)$ \\
Canada & $6.8(1990)$ \\
\hline
\end{tabular}

the number of home deliveries has slowly decreased but is still more than $30 \%$ (table 8 ). Provisional data show that eight countries have now an infant mortality rate of less than $7 \cdot 0$ per 1000 live births (table 9). The age of mothers delivering their first babies is continuously increasing. The average age of mothers of all liveborn babies in 1991 was 29.4 years. There has been an increase in the number of multiple births from 9.8 per 1000 live births in 1975 to 13.6 per 1000 in 1989 . About $25 \%$ of this increase is due to in vitro fertilisation. Problems related to pregnancy and birth increase with the age of the mother and are more often seen after assisted reproduction, particularly low birth weight and preterm birth is seen more frequently in this group. In a recent national study it was found that in $19891.6 \%$ of all live births were admitted to hospital for intensive care treatment.

Neonatal intensive care treatment is now limited to 10 centres (eight university hospitals and two large non-university hospitals). There is excellent cooperation between paediatricians and neonatologists, obstetricians, and clinical geneticists (prenatal diagnosis) and more and more at risk deliveries are concentrated in such perinatal centres. There has been an increasing demand for trained nurses and doctors in the neonatal intensive care units. Part of these service needs have been filled by house staff doctors who are not (yet) in a resident training position. There is a moral obligation to lift the numerous fixus regulation for residents in order to get these young doctors in a training position after at least two years. Another approach to the problem would be to train nurses for the type of work that is now being done by doctors.

\section{Medical ethical problems}

Modern technology and medical care make it possible to keep more children with severe and untreatable disorders alive. Medical ethical problems in paediatrics have now become a subject of ongoing debate within the professional organisations but also among ethicists, lawyers, politicians, and the public. In the Netherlands there has been an open discussion for years on the subject of medical decisions concerning the end of life. Recently the Dutch parliament passed a law on euthanasia. Every instance of euthanasia must be reported to the public prosecutor and will be evaluated by following the criteria set for careful performance of euthanasia. If the physician has acted in accordance with these criteria, prosecution usually will not follow, but cannot be ruled out. The law excludes individuals who cannot make a decision such as comatose patients and children. The law is based on a recent Dutch nationwide study on euthanasia and other medical decisions concerning the end of life. ${ }^{3}$ During recent years Dutch doctors have continually defended their position and have tried to explain the Dutch situation to their colleagues abroad. - $^{-6}$

The term euthanasia is used in the Netherlands only for active voluntary euthanasia in adults who can make their own decision. For alleviation of pain and/or other symptoms with high doses of opioids, for instance in a child who is in a terminal state of disseminated cancer with untreatable pain and suffering, the term euthanasia is not used. It is regarded as part of normal medical treatment. The physician has a duty to alleviate the pain and suffering of his patients and he may feel responsible for furthering the process of dying by using modern drugs available for pain relief. There is a wide consensus in the Netherlands that such treatment can be morally and legally justified.

In most situations - and certainly in the paediatric age group - the issue is about nontreatment decisions. Such decisions can be divided in two categories: (1) the decision not to start or prolong medical treatment because (further) treatment is evidently futile on medical grounds and (2) the decision not to start or prolong treatment because (further) treatment is considered to be against the best interests of the child. The first type of decision relates to, for instance, newborns with severe, untreatable congenital abnormalities that are not compatible with life. Again, there is a wide consensus that such decisions can be morally and legally justified. The second type of nontreatment decision relates to a complex area of situations about which no consensus exists in the Netherlands. Examples are newborns or infants with spina bifida, paralysed legs, and severe hydrocephalus and preterm infants who survive severe hypoxic ischaemic encephalopathy. It is a dilemma as to whether everything that is medically possible should be done for these patients. Complex issues are involved: When is stopping or continuing treatment in the best interests of the child? Which factors regarding the (future) quality of life should be taken into consideration and how should they be weighed? Who decides? Which procedures ought to be followed to guarantee a balanced and scrupulous decision making process?

The current situation in the Netherlands is that the Dutch Paediatric Society and the Dutch Medical Association have published reports in which proposals for general guidelines and procedures are given. The Dutch Health Council is preparing a report on these problems. There has not yet been an open political debate in parliament on these issues.

It is our impression that most people will accept that stopping or foregoing treatment in certain cases under procedural safeguards is ethically acceptable. From a legal point of view this category is, and probably will remain, a problem because in these cases the decision 
not to treat or to stop treatment is guided by a complex of intentions. Therefore, any decision to prosecute will depend on the individual circumstances of each case.

Meanwhile, in the Netherlands, physicians and parents together make the decision, in concrete situations, acting in the best interests of the child. It is our strong impression and our experience that in most cases physicians and parents after a scrupulous and careful decision making process, reach a consensus. In the large paediatric departments and children's hospitals in the Netherlands, medical ethical committees evaluate such decisions and the carefulness of the procedures. The district public prosecutor is also consulted.

The prevalence of active euthanasia in children in the Netherlands is, to our knowledge, extremely low. On active (by definition nonvoluntary) euthanasia in children there is no consensus here. For physicians, this type of decision is different from the type of decision not to start or to forego medical treatment. From a legal point of view one thing is certain: in such cases death is clearly intended and that means that the cause of death has to be reported as unnatural and will lead to an investigation by the public prosecutor.

Paediatricians who are 'euthanasia enthusiasts' do not exist. The only motivation for making medical decisions concerning the end of life in children, together with the parents, is the individual patient's best interests. In the well funded health care system in the Netherlands there is no incentive to have patients die soon. All facilities are available for the care of severely handicapped children.

\section{Non-therapeutic research in children}

Recently the Dutch government has sent a law proposal to parliament on medical experiments in humans. Therapeutic and non-therapeutic research in children is accepted but under strict guidelines. Non-therapeutic experiments in children should be controlled by a new central medical ethical committee. In the first discussion between government and parliament there was great concern in almost all political parties and it was suggested that nontherapeutic experiments be banned in children altogether. For obvious reasons Dutch paediatricians - particularly in academic centres - are alarmed by these developments. A ban on non-therapeutic research in children would stop a greater part of paediatric research and would not be in the interests of children in general.

Both the British Paediatric Association and the Canadian Paediatric Society have recently published reports on research involving children, and both societies eloquently defend nontherapeutic research in the paediatric age group albeit under strict conditions. ${ }^{78}$ Arguments on the ethical and legal principles of research on children have been repeatedly debated in the medical literature during the last decades and the greatest majority of authors have pointed out that non-therapeutic research on children should be acceptable with limitations. ${ }^{9-15}$

It is justified to involve children in nontherapeutic research that is judged to be low risk or low harm. Such research includes the collection of data on normal growth and development in the broadest sense (also blood values) and the assessment of diagnostic methods. Indeed by prohibiting non-therapeutic research in children - and not in adults! one denies the advantages of such investigations to the paediatric age group as a whole and this would treat children unjustly.

1 Starfield B. Primary care and health. A cross-national comparison. FAMA 1991; 266: 2268-71.

Wegman ME. Annual summary of vital statistics 1991 Pediatrics 1992; 90: 835-45.

3 Van der Maas PJ, van Delden JJM, Pijnenburg L, Looman CWN. Euthanasia and other decisions concerning the end of life. Lancet 1991; ii: 669-74.

4 Rigter H, Borst-Eilers E, Leenen HJJ. Euthanasia across the North Sea. $B M F$ 1988; 297: 1593-4.

5 Sauer PJ. Ethical decisions in neonatal intensive care units: the Dutch experience. Pediatrics 1992; 90: 729-32.

6 Visser HKA, Aartsen HGM, de Beaufort ID. Medical decisions concerning the end of life in children in the Netherlands. Am $\mathcal{F}$ Dis Child 1992; 146: 1429-31.

7 Ethics Advisory Committee. Guidelines for the ethical conduct of medical research involving children. London: British Paediatric Association, August 1992.

8 Consent Panel Task Force of the National Council on Bioethics in Human Research, with the support of the Canadian Paediatric Society. Report on research involving children. Ottawa: Canadian Paediatric Society, May 1992

9 Curran WJ, Hyg SM, Beecher HK. Experimentation in children. A re-examination of legal ethical principles. children. A re-examination
fAM $1969 ; 210: 77-83$.

10 The ethics of research involving children as controls [Editorial]. Arch Dis Child 1973; 48: 751-2.

11 Lowe CW, Alexander D, Mishkin B. Non-therapeutic research on children: an ethical dilemma. $\mathcal{F}$ Pediatr 1974 84: 468-72.

12 McCartney JJ. Research on children. National commission says 'yes, if . . ' Hastings on Hudson, NY; Hastings Centre Report, October 1978: 26-31.

13 Anonymous. Research involving children - ethics, the law, and the climate of opinion [Editorial]. Arch Dis Child 1978; 53: 441-2

14 Dworkin G. Legality of consent to non-therapeutical medical research on infants and young children. Arch Dis medical research on infan

15 Nicholson R, ed. Medical research with children: ethics, law and practice. Oxford: Oxford University Press, 1986. 